\title{
Vorwort zur fünfundzwanzigsten Auflage
}

Die 25. Auflage wurde zugunsten einer Vereinheitlichung der Formate in einer neuen Type gesetzt und erscheint daher bei ungekürztem Inhalt in verminderter Seitenzahl. Sie wurde wie ihre Vorgänger wiederum an vielen Stellen sorgfältig verbessert und ergänzt und nach Möglichkeit auf den neuesten Stand gebracht. Sonstige Änderungen, wie sie sich aus rein methodischen Gründen angesichts des ständigen Zustroms von Material im Lauf der Zeit immer wieder als wünschenswert ergeben, wurden mit Rücksicht auf die durch den Krieg bedingten Beschränkungen vorerst noch zurückgestellt. Doch bot sich diesmal die willkommene Gelegenheit, einen Abschnitt über Einrichtung und Benutzung der wichtigsten registrierenden Werke auf dem Gebiet der organischen Chemie anzufügen. Der Student kann sich mit diesen Hilfsnitteln nicht früh genug vertraut machen. Er wird auch von der Lektüre des Lehrbuchs um so größeren Gewinn haben, je eher er in der Lage ist, seine Kenntnisse von Fall zu Fall durch Einsicht der Original-Literatur zu erweitern und zu vertiefen. Ich habe deshalb Wert darauf gelegt, die organische Systematik zwar nur in den Grundzügen, aber doch so eingehend zu behandeln, daß dieser Abschnitt für den Anfänger als wirkliche Arbeitsanweisung betrachtet werden kann.

Z. Zt. Zobten (Bez. Breslau), im April 1944.

Friedrich Richter

\section{Vorwort zur sechsundzwanzigsten Auflage}

In nicht abreißendem und fast unübersehbarem Strom ergießen sich seit einigen Jahren die Forschungsergebnisse der Kriegs- und Nachkriegszeit in die wissenschaftliche Literatur. Der Zuwachs an Kenntnissen ist auch bei zurückhaltender Beurteilung achtunggebietend, die damit verbundene Weitung des allgemeinen Gesichtskreises nicht ninder eindrucksvoll. Die 26. Auflage sucht dem bei zunächst noch unveränderter Anlage Rechnung zu tragen und ist wieder sorgfältig dem Stand der Forschung angepaßt. Fast auf jeder Seite wird der aufmerksame Leser entsprechenden Ergänzungen oder Änderungen begegnen. Sie erstrecken sich ebensowohl auf die organische Chemie klassischer Prägung, die mit der ihr eigenen Methodik und Intuition das Feld in unverminderter Lebenskraft beherrscht, wie auf ihre Verknüpfung mit physikalischtheoretischen und biochemischen Beziehungen, aus denen sie ständig neue Impulse von steigender Wichtigkeit erhält. Daß das Lehrbuch im vergangenen Jahr auf das nicht gerade häufige Ereignis eines 50 jährigen Bestehens zurückblicken konnte, verdankt es wohl vornehmlich eben der Betonung des Grundsätzlichen und dem Streben nach Einheit der theoretischen Vorstellungen, auf denen das Wundergebäude der organischen Strukturchemie ruht. Kein Erbe, dessen Besitz nicht auch hier ständig neu erworben werden müßte. Der große Wandel in den Verfahren der Technik hat in der vorliegenden Auflage gleichfalls in vielen Beispielen seinen Niederschlag gefunden.

Wie in den Vorjahren bin ich auch diesmal zahlreichen Fachgenossen, unter denen ich besonders Herrn Prof. Otto Bayer hervorheben möchte, für wertvolle Ratschläge und Auskünfte zu Dank verpflichtet.

Frankfurt a. Main, im Oktober 1949. 